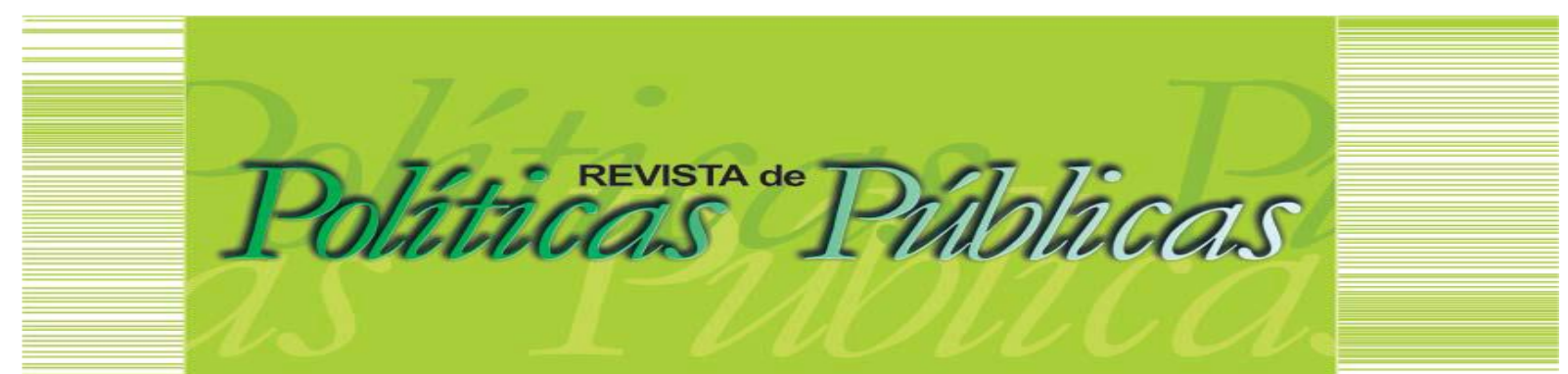

\title{
PROJETOS SOCIETÁRIOS EM TEMPOS DE PANDEMIA E O EXERCÍCIO PROFISSIONAL DE ASSISTENTES SOCIAIS DO PARÁ
}

\author{
Cilene Sebastiana da Conceição Braga1 \\ Ediane Moura Jorge ${ }^{2}$ \\ Lais Ribeiro Gama ${ }^{3}$ \\ Mickaely de Lima Gomes ${ }^{4}$
}

\section{Resumo}

Este artigo expõe os resultados parciais da pesquisa intitulada "Projetos Societários em disputa em tempos de pandemia e o exercício profissional do Assistente Social do Pará/Amazônia legal" vinculada a um Grupo de Estudos da UFPA. Apresenta o levantamento da literatura pertinente ao tema produzida por Assistentes Sociais e publicada em periódicos. Apresenta dados acerca do número de infectados na região Amazônica, especificamente no Estado do Pará. Analisa os dados a partir de uma perspectiva teórica-crítica. Realizamos pesquisa bibliográfica e pesquisa documental. $O$ artigo exibe breves reflexões sobre a realidade socioeconômica na pandemia na Região Amazônica e no Estado do Pará,e principais problematizações em termos de ausência de direitos sociais e desafios para o (a) Assistente Social. Os resultados mostram que os (as) assistentes sociais enfrentam 0 medo, a insegurança e o deterioramento das condições de trabalho no enfrentamento da pandemia.

Palavras-chave: Pandemia. Exercício Profissional. Neoliberalismo. Precarização. Amazônia.

\section{SOCIAL PROJECTS IN PANDEMIC TIMES AND THE PROFESSIONAL EXERCISE OF SOCIAL WORKERS IN PARÁ}

\begin{abstract}
This article exposes the partial results of the research entitled "Corporate Projects in dispute in times of pandemic and the professional practice of the Social Worker of Pará / Legal Amazon" linked to a UFPA Study Group. It presents a survey of the pertinent literature produced by Social Workers and published in periodicals. It presents data about the number of infected in the Amazon region, specifically in the State of Pará. The data are analyzed from a theoretical-critical perspective. We carry out bibliographic and documentary research. The article shows brief reflections on the socioeconomic reality in the pandemic in the Amazon Region and in the State of Pará, and main problems in terms of the absence of social rights and challenges for the Social Worker. The results show that social workers face fear, insecurity and deteriorating working conditions in the face of the pandemic.
\end{abstract}

Keywords: Pandemic. Professional Practice. Neoliberalism, Precariousness. Amazon

Artigo recebido em: 21/12/2020 Aprovado em: 27/05/2021

DOI: http://dx.doi.org/10.18764/2178-2865.v25n1p212-227

\footnotetext{
${ }^{1}$ Assistente Social. Doutora em Política Social pela Universidade de Brasília. Professora Permanente do Programa de PósGraduação em Serviço Social (PPGSS) da Universidade Federal do Pará (UFPA). E-mail: cilene@ufpa.br

2 Mestre em Serviço Social pela Universidade Federal do Pará. Doutoranda do Programa de Pós-Graduação em Serviço Social (PPGSS) da Universidade Federal do Pará (UFPA). E- mail: edianemj@gmail.com

${ }^{3}$ Estudante do Bacharelado em Serviço Social pela Universidade Federal do Pará. Bolsista do Programa Institucional de Bolsas de Iniciação Científica (PIBIC). E-mail: laisgama.r@gmail.com

${ }^{4}$ Estudante do Bacharelado em Serviço Social pela Universidade Federal do Pará. Bolsista do Programa Institucional de Bolsas de Iniciação Científica (PIBIC). E-mail: mikaelly.gomes.ml@gmail.com
} 


\section{INTRODUÇÃO}

Este trabalho apresenta os primeiros resultados de um projeto de pesquisa intitulado "Projetos Societários em disputa em tempos de pandemia e o exercício profissional do Assistente Social do Pará/Amazônia legal" que se vincula ao Grupo de Estudos, Pesquisa e Extensão em Serviço Social e Política Social na Amazônia e visa identificar e analisar as relações do exercício profissional de assistentes sociais do Estado do Pará em tempos de pandemia/COVID-19.

Visando conhecer a realidade de trabalho dos(as) assistentes sociais no estado estamos utilizando vários procedimentos de coleta de dados,aplicando um formulário eletrônico para assistentes sociais ativos no Estado do Pará, que contém questões objetivas e subjetivas. Além disso, estão sendo realizadas análises e atualização bibliográfica especializada referentes ao tema de pesquisa, utilizando recursos disponiveis em bibliotecas, periódicos e livros de seu acervo ou fontes secundárias e, também por meio de acesso a fontes disponibilizadas na internet. Também, realizamos pesquisa bibliográfica e pesquisa documental.

Neste trabalho apresentaremos pontuações iniciais acerca da realidade da pandemia no Estado do Pará a partir de levantamento bibliográfico e número de infectados de fontes extraídas de sites oficiais como IBGE, Ministério da Saúde e outros. O levantamento bibliográfico teve como fontes principais artigos cientificos extraídos da plataforma Scientific Electronie Library Online (Scielo),realizado durante o primeiro ano de pandemia, em 2020, bem como mapeamento de livros publicados em 2020 que tratavam do tema, como o e-book "Serviço Social em Tempos de Pandemia: provocações ao debate", que reúne uma série de relatos de experiências de diferentes áreas de atuação, durante o enfrentamento da pandemia no Brasil. Essas informações foram problematizadas a partir da perspectiva teórica-crítica, buscando apresentar o processo de exploração e desigualdade vividas na Amazônia legal, especificamente no Estado do Pará e os impactos na vida dos trabalhadores e trabalhadoras da região e no cotidiano de Assistentes Sociais.

Este trabalho será dividido em três momentos: no primeiro, a introdução apresentando a temática que será trabalhada; no segundo, breves considerações sobre a realidade socioeconômica e da pandemia na Região Amazônica e no Estado do Pará no contexto do fortalecimento do neoliberalismo;por último, principais problematizações em termos de ausência de direitos sociais e desafios para o (a) Assistente Social. 


\section{PANDEMIA NA REGIÃO AMAZÔNICA E NO ESTADO DO PARÁ NO CONTEXTO DO FORTALECIMENTO DO NEOLIBERALISMO}

O enxugamento do Estado e o aumento da barbárie são problematizações pontuadas por vários autores, como Ricardo Antunes (1995), Marildo Menegat (2006), David Harvey (2008), István Mészáros (2013) entre outros, e se apresentam no contexto neoliberal desde a década de setenta, no mundo. No Brasil, o neoliberalismo se manifesta nas contradições presentes na efetivação da política social e no que Behring (2003) denomina contrarreforma do Estado, que envolve a desestruturação do Estado e a perda dos direitos sociais. Após o golpe de 2016 ${ }^{1}$, esse processo aumentou, visto que 0 governo de Michel Temer "empreendeu medidas políticas e administrativas com impactos nas políticas sociais", através de uma onda de reformas que afetaram principalmente a classe trabalhadora (SOARES; NOBRE, 2018, p. 800), medidas que foram seguidas e agravadas pelo governo Bolsonaro.

As crises apresentadas durante 0 primeiro ano do governo Bolsonaro foram materializadas na grande taxa de desemprego, fechamento de fábricas, aumento do uso de agrotóxicos, aumento do feminicídio, no racismo, além de uma crise ambiental como nunca vista na história. Na região amazônica houve o aumento de $55 \%$ de desmatamento, segundo registros do Instituto Nacional de Pesquisas Espaciais (INPE), na comparação entre $01^{\circ}$ quadrimestre de 2019 e 0 de 2020. A luta em prol da preservação da Amazônia deve ser vislumbrada no contexto da luta de classes, marcada por constantes crises de cunho político, econômico e social.

Tal conjuntura da gestão federal, que denominamos de "desgoverno",tem sido para a classe trabalhadora um governo que caminha ao lado da elite brasileira e que apresenta atributos com avanços conservadores, que trazem para o capitalismo brasileiro traços da barbárie.

Netto (2008), em um evento internacional realizado na Bahia para Assistentes Sociais, destacava que a Barbárie se apresenta em três dimensões. A primeira é a naturalização da pobreza: observa-se aumento gigantesco de pobres no mundo em função das medidas assumidas com as diretrizes neoliberais e ninguém assume apresentar suas reais causas e lutar em prol da supressão da pobreza. A criminalização da população pobre e o extermínio da juventude nas periferias do estado do Pará comprovam isso. O Pará está entre os 10 estados com maiores taxas de homicídios de jovens entre 15 e 29 anos (IPEA, 2020) e essas taxas vêm crescendo de forma assustadora. Um estudo recente sobre o extermínio da juventude (ultra)periférica na Amazônia destacou que 44,2\% das pessoas vítimas de homicídio no estado do Pará entre 2010 e 2018 eram crianças, adolescentes e jovens de 0 a 29 anos, o que caracteriza um verdadeiro massacre da juventude, que vem sendo 
legitimado por meio da criminalização dessa população pobre, negra e periférica em sua maioria (DELUCHEY, 2019). Conforme destaca Mendes (2013, p. 7):

[...] Assim, a mídia produz e reforça a construção de estereótipos com relação aos jovens moradores de periferias e favelas, contribuindo para que eles sejam vistos como 'infratores', 'violentos', 'perigosos' e merecedores do extermínio. 0 jovem passa a ser o "bandido" em enunciados construídos ideologicamente com o intuito de propagar e ativar uma memória discursiva que produz no leitor gestos de leitura que confirmam a percepção da juventude como autora da violência, sem maior contextualização ou reflexão.

A figura da juventude pobre como responsável pela violência e não como vítima dela é consolidada através de noticiários e matérias de jornais populares com temas pejorativos atribuídos a essa juventude popular, como se a periferia fosse um espaço social que só produz criminosos, onde a pobreza é sinônimo de violência.

A segunda dimensão apresentada pelo autor é a criminalização do "dissenso político": qualquer projeto nacional ou societário que discrepe das diretrizes da ordem "globalizada" é apontado como "terrorismo". No Brasil, essa relação é vivida intensamente no atual governo, que ameaça de todas as formas quem diverge de sua postura autoritária. A terceira e última dimensão da barbárie contemporânea apresentada por Netto é a negação absoluta de qualquer alternativa à ordem global vigente, ou seja, o capitalismo. No Brasil observa-se perseguição a qualquer tipo de posição contrária ao que está posto pelo governo: ser crítico passou a ser alvo de todos os tipos de perseguição.

O cenário marcado por esse conjunto de restrições no campo do direito e aumento da barbárie colocou o Brasil em um cenário muito delicado em 2020, momento em que o mundo passou a enfrentar a epidemia da COVID-19. Então quando a epidemia passou a atingir a população brasileira, o país já vinha enfrentando vários problemas relacionados ao enxugamento do Estado e ao aumento da barbárie; a COVID-19 acrescentou mais calamidade a uma população em situação de barbárie.

Desse modo, atingindo também profissionais do Serviço Social, que já enfrentavam limitações nos espaços sócio-ocupacionais e também no campo formativo. Assistentes sociais tiveram de responder às demandas apresentadas pelos usuários em tempo de pandemia e conseguir ter uma leitura mais profunda dos limites institucionais, considerando que várias limitações ao trabalho não se restringiam às questões locais, mas sim ao desmonte nacional de políticas públicas no enfrentamento à pandemia de COVID-19.

Observa-se que a ofensiva neoliberal não conseguiu responder às necessidades da população em tempos de Pandemia mundial. Mas, no Brasil, a ausência de respostas por parte do Estado foi maior do que em outros países: a omissão do Estado no atendimento e construção de uma política nacional para deter a pandemia resultou em um número significativo de profissionais da saúde e da assistência social que foram a óbito, além de um número gigantesco de outros brasileiros - até o 
dia 08/12/2020, segundo o Painel Coronavírus do Ministério da Saúde, havia 178.159 óbitos (MINISTÉRIO DA SAÚDE, 2020). A área da enfermagem foi a que mais apresentou número de óbitos. O "Brasil acima de tudo e de todos" passou a assumir lugar significativo em número de mortos em todo o mundo, acima de outros países, de acordo com o Conselho Internacional de Enfermeiros (ICN).

Observou-se no Brasil o intenso aumento da precarização do trabalho e da desproteção de assistentes sociais em seus espaços sócio-ocupacionais diversos. Portanto, diante desse cenário, compete-nos analisar a expansão da pandemia em uma conjuntura de ampliação do neoliberalismo e as suas consequências na Amazônia.

A expansão do neoliberalismo contribuiu para o fato de que, desde os Anos 80, o mundo passou por quatro grandes epidemias (ebola, SARS, MERS e agora covid-19)2, sendo a aplicação de suas políticas - ou seja, desregulamentação dos mercados e sua globalização, bem como políticas de austeridade social - um dos fatores que mais contribuíram para a disseminação de tais doenças nos dois lados do Atlântico Norte. Isso explica porque elas adquiriram grande visibilidade da mídia, pois também existiram outras epidemias que não afetaram esses países e ficaram limitadas e contidas nos países subdesenvolvidos ou em outros continentes, e dificilmente foram notícia (NAVARRO, 2020).

Isto nos impõe inúmeros desafios para a materialização de uma proposta que busque outra sociabilidade e para isso é necessário analisar as condições, relações, limitações e os avanços do exercício profissional dos (das) assistentes sociais nos espaços sócio ocupacionais no Estado do Pará em Tempos de pandemia. Destaca-se que um dos desafios postos aos Assistentes Sociais no contexto do neoliberalismo diz respeito a assumir a direção política em consonância com o Projeto Ético-Político (PEP) do Serviço Social brasileiro, que entra em choque com a conjuntura de superexploração do trabalho e aumento de demandas dos serviços dos profissionais.

\section{DESAFIOS AOS IÀS ASSISTENTES SOCIAIS EM TEMPOS DE PANDEMIA}

Ressalta-se que no atual contexto de pandemia e avanço do neoconservadorismo no Brasil, bem como regressão de direitos sociais, é imprescindível que possamos conhecer os desafios e avanços da intervenção profissional nessa conjuntura. Visto que a realidade é dialética e nos obriga a buscar novas estratégias de enfrentamento, compreendendo o que Marx chamou de "uma grande ideia fundamental", a saber, "de que não se pode conceber o mundo como um conjunto de coisas acabadas, mas como um conjunto de processos" (MARX-ENGELS, 1963, p. 195).

No Brasil e no Estado do Pará vive-se um contexto de medos, marcado pela ausência de um sistema adequado de saúde que atenda a população brasileira, tanto no que diz respeito a sua 
sobrevivência diante da COVID-19, como de sobrevivência pós-pandemia, e, em particular, as comunidades ribeirinhas, aldeias indígenas e outras comunidades presentes no espaço da Amazônia Legal, Estado do Pará. Esses espaços apresentam grandes desafios no que tange ao saneamento básico, à moradia, e a outras questões particulares de quem vive nessa região.

São 161 povos no Brasil que já vivenciam a crise sanitária, e foram registrados 40.845 indígenas infectados e 884 mortes, segundo a Secretaria Especial de Saúde Indígena (SESAI) e Comitê Nacional de Vida e Memória Indígena. Segundo o último relatório da Articulação dos Povos Indígenas do Brasil (APIB, 2020), o governo federal é o principal agente transmissor da covid19.Abaixo segue o destaque do relatório para o Amazonas, que foi o primeiro estado que confirmou a contaminação de indígenas e está concentrando o maior número de óbitos e o alcance de povos isolados no Vale do Javari (Figura 1). As denúncias do relatório expõem a ausência de informações pelo governo federal e apontam racismo institucional da SESAI. Os povos indígenas em todo o Brasil estão sendo negligenciados pelo governo federal.

Figura 1 - Contaminação de povos indígenas

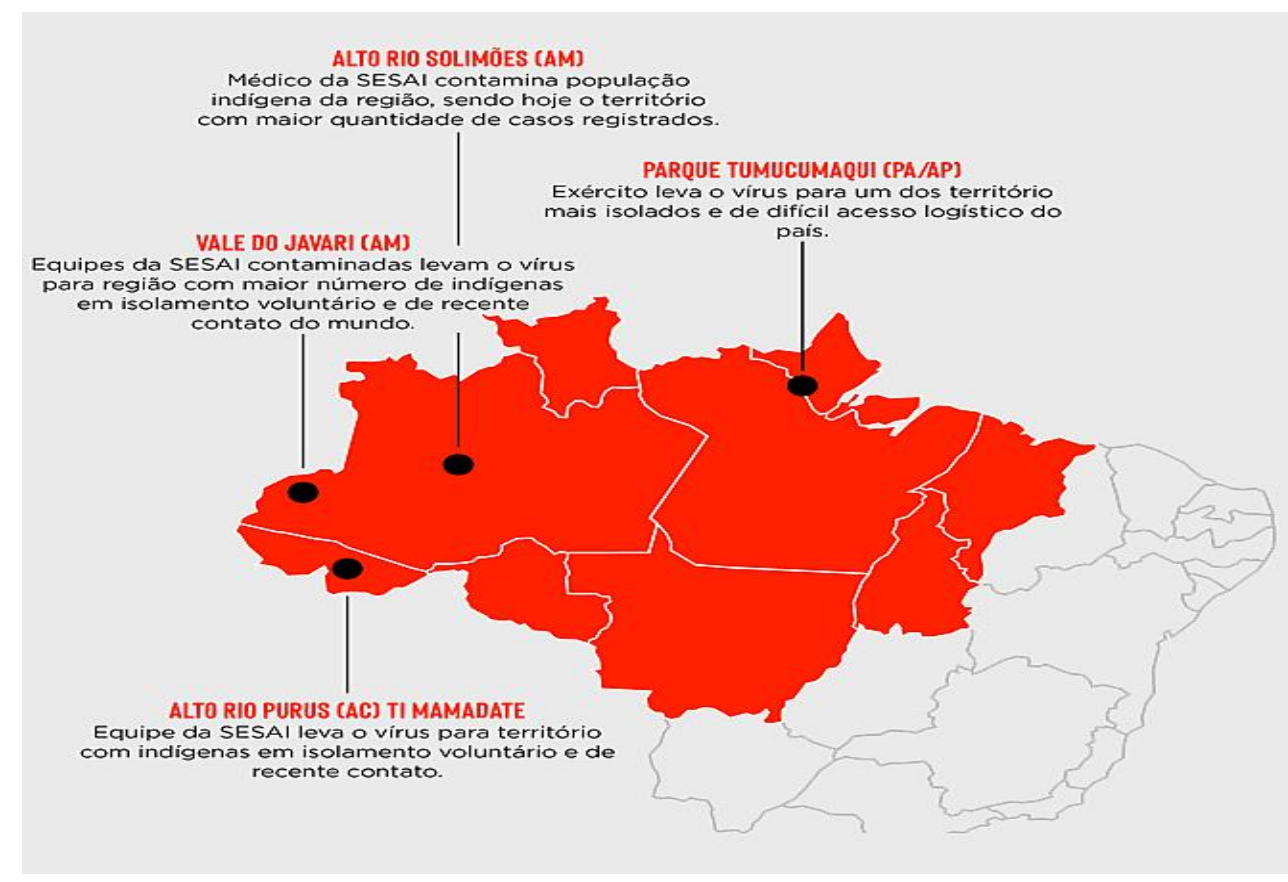

Fonte: Relatório APIB, 2020.

No Norte seguem dados do Ministério da Saúde: 18.430 .980 total de casos, 40.822 óbitos (28/05, M. SAÚDE, 2021). São dados que nos revelam o crescente número de casos e nos levam a mais informações de desigualdades: globalmente há evidências que mostram as diferenças na resposta imune à COVID-19 entre homens e mulheres. Embora 60\% dos casos sejam atribuídos aos homens, as mulheres apresentam uma melhor resposta imune ao vírus. Estudos estão sendo realizados para codificar como ambos reagem à infecção. 
O que podemos refletir destes dados? 0 público atendido em sua grande maioria por assistentes sociais são mulheres. Desta forma, com um índice alarmante de letalidade da COVID-19 em homens, há a necessidade de refletir como a pandemia tem afetado a vida de mulheres pobres, periféricas e negras, que passam a ocupar um novo papel social como chefes de família, que chegam aos espaços de atendimento em busca de benefícios para a ausência provedora do homem que mantinha a família. Além do papel como dona de casa e responsável primária pelo cuidado e educação dos filhos, a pandemia trouxe este novo desafio para a provedora da família.

Assim, o presente trabalho também é resultado de reflexão teórica de ações desenvolvidas pelo Grupo de Estudos (GEPSS) no Pará, tanto no campo da pesquisa em serviço social como no campo da Extensão. Na extensão foram desenvolvidas ações de formação continuada em 2019, alcançando mais de 100 profissionais de Serviço Social que atuam na região metropolitana de Belém e outros municípios do Estado do Pará. Essa experiência resultou na apresentação durante as aulas, por parte dos profissionais, dos desafios enfrentados cotidianamente no que tange às condições e relações de trabalho precarizadas, assim como os impactos vividos nas áreas da Assistência Social e Saúde em função da redução de gastos, o que cria tensões no campo da política social e na efetivação dos direitos sociais.

Nas atividades de pesquisa observam-se diversas fragilidades no campo da formação profissional no que diz respeito à compreensão das dimensões teórico-metodológica e ético-política, o que resulta na dificuldade de apreender o debate da relação teoria-prática no campo do Serviço Social. O tecnicismo presente no cotidiano profissional, o pragmatismo e a ausência de conhecimento do real significado do projeto ético-político e das diretrizes legais que permeiam o Serviço Social colocam a profissão frente a um conjunto de fragilidades no interior das Instituições/espaços sócio-ocupacionais dos Assistentes Sociais na região.

O cenário de pandemia intensificou essas fragilidades e trouxe à tona novos (e velhos) desafios à profissão. Ainda há poucos estudos a respeito desses desafios, afinal a pandemia ainda está em curso. Porém, realizamos um levantamento bibliográfico onde foram encontrados trabalhos relevantes ao tema proposto. Assim, temos relatos de experiência e pesquisas em andamento de profissionais do Serviço Social que estão enfrentando a pandemia da COVID-19 em diferentes áreas de atuação. Reunimos e sistematizamos os desafios em comum mais frequentes para o Serviço Social, extraídos de artigos científicos e do e-book "Serviço Social em Tempos de Pandemia: provocações ao debate", que reúne vários trabalhos de assistentes sociais que estão construindo estratégias de enfrentamento dos desafios postos pela pandemia, a saber:

a) Dificuldades de aquisição de EPIs (SILVA; SILVA, 2020); 
b) A necessidade de mudança da localização da sala de atendimento do Serviço Social por não contemplar os critérios de distanciamento e ventilação necessários (SILVA; SILVA, 2020);

c) Diminuição do quadro de assistentes sociais devido ao afastamento de profissionais que integram o grupo de risco (BARROS, 2020);

d) O medo do contágio da COVID-19 devido à falta de equipamentos e espaços de trabalho adequados, fragilizando emocionalmente os (as) profissionais e limitando a capacidade de enfrentamento da pandemia (VALE; NASCIMENTO, 2020);

e) Imposição de atribuições que não competem ao Serviço Social, entre elas, a comunicação de óbito (VALE; NASCIMENTO, 2020);

f) Adaptação ao trabalho remoto, via telefone e aplicativos de mensagens (OLIVEIRA, 2020);

g) Falta de recursos humanos e materiais para atender usuários em situação de rua (GOMES; VERAS, 2020);

h) Novas estratégias de enfrentamento da violência de gênero diante do isolamento social (LEAL; OLIVEIRA; BATISTA, 2020);

i) Dificuldade de garantir 0 atendimento aos usuários por vias remotas devido àexclusão digital de uma grande parcela do público-alvo das políticas sociais (CAVALCANTE; OLIVEIRA; MARQUES, 2020).

Conforme os estudos mencionados acima, os (as)assistentes sociais enfrentam 0 medo, a insegurança e o deterioramento das condições de trabalho diariamente no enfrentamento da pandemia. Entretanto, convém frisar que a precariedade dos espaços de trabalho e as dificuldades de recursos materiais e humanos já eram uma realidade do Serviço Social antes da pandemia (SANTOS; MANFROI, 2015). Tais problemas apenas se agravaram com a chegada da COVID-19, de uma forma devastadora, em especial, na área da saúde.

Os trabalhadores e trabalhadoras da área da saúde, o que inclui os (as) assistentes sociais, tiveram suas jornadas de trabalho intensificadas, férias suspensas e estão trabalhando presencialmente na linha de frente no combate à pandemia, lidando com perdas e com o medo do contágio da COVID-19 (MATOS, 2020). Os relatos de experiência que estão sendo produzidos confirmam que esses (as) profissionais estão sobrecarregados física e emocionalmente, e lidando com os problemas já mencionados de forma individual e coletiva através das entidades da categoria.

Portanto, é importante destacar que a profissão no Brasil ocupa uma diversidade de espaços sócio-ocupacionais, no entanto percebemos, no levantamento bibliográfico realizado, que as áreas da saúde e assistência social foram as mais enfatizadas, haja vista que tais profissionais 
encontram-se na linha de frente, junto a outros(as),no combate à pandemia do novo Coronavírus (Covid-19), reinventando-se e atuando nos determinantes que reconfiguram as expressões da "Questão Social", diante de um Sistema Único de Saúde - SUS e Sistema Único da Assistência SocialSUAS fragilizados e sucateados após os cortes de orçamento público do atual Estado ultraneoliberal.

Assim como Matos (2020), Silva et al.(2020) também apontam a falta de equipamentos de proteção como desafio para os Assistentes Sociais. Segundo a autora, por ser um trabalho que requer contato direto com os usuários, é indispensável a utilização de equipamentos de proteção individual (EPIs) seguros;contudo, vários profissionais vêm afirmando que não estão sendo assegurados os tais equipamentos, colocando a sua saúde em risco pela falta de viabilização de direitos da própria categoria, infringindo 0 artigo $7^{\circ}$ do código de ética, o qual destaca que as instituições públicas ou privadas devem dispor de condições de trabalho adequadas para garantir a qualidade do exercício profissional (BRASIL, 1993).

Outro importante desafio identificado foi a sobrecarga de trabalho tanto para os assistentes sociais como para os demais profissionais da saúde, ocasionada principalmente pela falta de contratação de pessoal, pelo absenteísmo, atestados médicos, já que alguns profissionais da área da saúde foram dispensados dos seus espaços sócio-ocupacionais, sem prejuízo de remuneração, seja por motivo de doença, ou por pertencer ao grupo de risco, sendo essas pessoas acima de 60 anos, portadores(as) de doenças crônicas como asma, hipertensão, diabetes, entre outros fatores. A partir disso, evidencia-se que houve uma incidência maior de profissionais submetidos ao excesso de trabalho, realizando plantões extras para atender às demandas do serviço. Além disso, sobre a área da assistência a autora expõe que:

A contratação de pessoal temporário é urgente e acentuada pelo novo contexto, mas as equipes de referência sempre foram defasadas e cada vez mais reduzidas no último ano. A ausência de concurso público, as contratações temporárias e precarizadas dos trabalhadores implicam em alta rotatividade profissional, o que inviabiliza continuidade de projetos e ações, bem como limita o conhecimento da abrangência territorial e suas particularidades (SILVA, 2020, p.65).

A exaustão física e mental à qual esses (as) profissionais estão expostos, devido à diminuição do quadro de assistentes sociais, compromete a saúde dos mesmos e a qualidade dos atendimentos aos usuários. Mesmo diante de um cenário de calamidade pública, ocasionado pela pandemia, se fazem necessárias medidas para diminuir os riscos que esses (as) profissionais vêm enfrentando.

De acordo com Silva et al.(2020), outro grave problema que vem sendo imposto no contexto atual é a atribuição por parte do Estado e das instituições empregadoras de funções que não fazem parte das atribuições e competências profissionais (VALE; NASCIMENTO, 2020) instituídas na 
lei que regulamenta a profissão. Ainda de acordo com a autora, são requisitadas ao profissional de serviço social ações como: comunicação de óbito, marcação de exames, solicitação de medicamentos de alto custo, alta hospitalar, identificação de vagas em outras unidades de saúde para transferência de pacientes, dentre outras ações que são de caráter técnico-administrativo, não sendo função dos assistentes sociais (SILVA et al., 2020).

Diante de tal situação, em março de 2020, o Conselho Federal de Serviço Social divulgou a Orientação Normativa 3/2020, que trata sobre ações de comunicação de boletins de saúde e óbitos por assistentes sociais. A normativa esclarece, dentre outras questões, que, não só referente ao exercício profissional durante a pandemia do novo Coronavírus (Covid-19), mas no cotidiano do trabalho profissional, a comunicação de óbito não se constitui atribuição ou competência profissional do (a) assistente social, sendo uma responsabilidade dos profissionais qualificados e que tenham conhecimentos específicos como médico, enfermeiro (a), psicólogo (a) e/ou outros profissionais (CFESS, 2020).

Percebemos o quanto é necessário que o profissional conheça o real significado do projeto ético-político e das diretrizes legais que permeiam o Serviço Social, para que possa, junto com a categoria da profissão, reafirmar o seu verdadeiro papel na divisão sociotécnica do trabalho, não retrocedendo ao tradicionalismo e fortalecendo o reconhecimento social da profissão ante a sociedade.

Essas fragilidades evidenciadas nas pesquisas demandam dos (das) Assistentes Sociais intervenções fundamentadas nos campos teórico, metodológico e político para o enfrentamento das adversidades particulares do contexto neoliberal brasileiro (IAMAMOTO, 2006). O Estado brasileiro apresenta prioridades pautadas nos interesses do mercado em detrimento dos da classe trabalhadora. O atendimento das necessidades humanas é colocado em segundo plano, e as prioridades do capital e os lucros colocam-se acima de qualquer outra demanda, acima da vida.

Dessa forma, evidencia-se a necessidade de conhecer com mais profundidade os desafios presentes no cotidiano de Assistentes Sociais do Pará para que se busque construir mecanismos e criar diferentes estratégias, individuais e coletivas, para a defesa dos direitos sociais e humanos, bem como das políticas públicas no Pará e no Brasil.

Cabe destacar que o Conjunto CFESS-CRESS apresentou por meio do CFESSMANIFESTA nota sobre "Os impactos do Coronavírus no trabalho do (a) assistente social", que mostrou orientações sobre o trabalho dos Assistentes Sociais em meio à pandemia do Coronavírus. $\mathrm{A}$ nota foi construída pela Comissão de Orientação e Fiscalização (Cofi/CFESS). 0 documento destaca a necessidade de cobrar, inclusive de forma articulada ao movimento sindical, meios de garantir as condições éticas e técnicas adequadas para o exercício profissional (conforme disposto na Resolução CFESS $\left.n^{\circ} 493 / 2006\right)$ nesse momento particular que a sociedade vive. 
Diante dessa realidade, observa-se a imprescindibilidade de fortalecer conhecimentos e competências profissionais em face do Projeto Ético-Político e dos direitos sociais para profissionais que trabalham em diversos municípios e políticas sociais no Estado do Pará, com a proposta de compreender e absorver cientificamente as demandas postas nessa conjuntura e as possibilidades de mediações para o desenvolvimento do trabalho de assistentes sociais.

Os estudos acima abordados mostram a necessidade de conhecer como estão intervindo os (as)assistentes sociais nos municípios mais afetados pelo Novo Coronavírus (SARS-CoV-2), bem como os impactos da pandemia nas condições de trabalho desses profissionais. Assim, a proposta torna-se essencial para tomar conhecimento e propor alternativas ao trabalho e para a efetivação das políticas sociais no Pará, "[...] os rumos e estratégias de ação são estabelecidos a partir da elucidação das tendências presentes no movimento da própria realidade, decifrando duas manifestações particulares no campo sobre o qual incide a ação profissional [...]" (IAMAMOTO, 2009, p. 3).

Atualmente o Serviço Social está voltado para a defesa de trabalhadores e trabalhadoras; o compromisso com a liberdade, com a democracia e a afirmação de direitos. Portanto, em qualquer espaço profissional que atue, o(a) assistente social terá como base o código de ética, o projeto éticopolítico e as diretrizes curriculares. O neoliberalismo, em contrapartida, atinge os espaços sócioocupacionais em que tais profissionais trabalham, buscando segmentar os(as) usuários(as). Dessa forma, na conjuntura de pandemia se postam outros desafios que necessitam ser investigados. Mas a leitura do profissional deve ser baseada na totalidade. Isso somente é possível com a utilização de sua capacidade teleológica no cotidiano do trabalho, imprimindo a necessidade e compromisso éticopolítico de repensar as práticas profissionais em tempos de crise.

\section{CONSIDERAÇÕES FINAIS}

Refletimos que no Brasil observa-se uma conjuntura de extrema direita e um ultraneoliberalismo que tenta aniquilar oposições e contradições. Ser crítico da sociedade e estado atual da contemporaneidade brasileira exige expor a situação do país em uma realidade pandêmica com a maior riqueza de dados científicos possíveis. Aqui, apresentamos dados parciais da pesquisa "Projetos Societários em disputa em tempos de pandemia e o exercício profissional do Assistente Social do Pará/Amazônia legal" objetivando trazer ao debate nacional um contexto da vivência da sociedade amazônica e da realidade de seus (suas) profissionais em espaços de trabalho que vêm exigindo nesta conjuntura de crise sanitária e econômica que assistentes sociais possam responder àsdemandas postas com rapidez e devidas competências técnicas, teóricas e éticas. 
Os dados parciais demonstram que as práticas profissionais exercidas em tempos complexos desta pandemia no Brasil intensificaram a exploração do trabalho de assistentes sociais e a precarização e desproteção nos espaços sócio-ocupacionais, desde a falta de EPIs para o desenvolvimento das atividades profissionais,até exigências aos serviços, que muitas vezes chegam a desvios de funções e atribuições privativas das (dos) assistentes sociais no Pará. Isso ante uma expansão do conservadorismo neoliberal na Amazônia.

Portanto, como reflexão conclusiva, consideramos que os desafios citados e postos na realidade e cotidiano de muitos profissionais requerem uma compreensão das condições objetivas, sociais e históricas da atual conjuntura na região amazônica e nacional para reflexão crítica somada com mobilizações coletivas que lutem por direitos ao uso de equipamentos de proteção individual (EPIs) seguros e por melhores condições concretas de realização do exercício profissional.

A realidade de trabalho de assistentes sociais, aqui refletida,apresenta contradições e obstáculos. Analisar o conjunto requer compreender que estas relações em conjunto no trabalho são produtos de condições históricas e possuem limites e determinações dentro de circunstâncias específicas, e as formas de ser determinadas nesta sociedade capitalista exigem cada vez mais conhecimento, habilidades e competências de assistentes sociais.

Este estudo, também, leva-nos a uma aproximação provisória para significar que, nesse contexto da prática profissional em tempos de pandemia, necessitamos de formação continuada e de articulação e mobilização coletiva das (dos) profissionais na defesa de uma profissão que tem buscado realizar um trabalho de resistência ao lado da classe trabalhadora, desenvolvendo uma vanguarda na direção de um exercício profissional que mantenha ativas as dimensões ético-política, teóricometodológica e técnico-operativa da profissão no país.

Dessa forma, nossa reflexão é que os desafios presentes no cotidiano de Assistentes Sociais do Pará requerem a busca por criação de estratégias individuais e coletivas para a defesa da profissão e direitos sociais no Pará e Brasil, objetivando sempre a emancipação humana (MARX, 2009).

\section{REFERÊNCIAS}

ANTUNES, Ricardo. Adeus ao trabalho? Ensaios sobre as metamorfoses e a centralidade do mundo do trabalho. Campinas, SP: Cortez. 1995.

APIB, Articulação dos Povos Indígenas do Brasil. Nossa luta é pela vida. COVID-19 e povos indígenas: 0 enfrentamento das violências durante a pandemia. Relatório, 2020. 
BARROS, Adriana Lima. O Trabalho do/a Assistente Social no Contexto Hospitalar em Tempos de Pandemia: um relato de experiência do hospital estadual Dirceu Arcoverde de Parnaíba. In: PEREIRA, S. L. B; CRONEMBERGER, I. H. G. M. (org). Serviço Social em Tempos de Pandemia: provocações ao debate. Cap. 2. Teresina: EDUFPI, 2020. Disponível em:

https://ufpi.br/arquivos_download/arquivos/Servi\%C3\%A7o_Social_em_tempos_de_pandemia_provoc a\%C3\%A7\%C3\%B5es_ao_debate_120200923104616.pdf. Acesso em: 10 dez. 2020.

BEHRING, Elaine Rossetti. Brasil em Contrarreforma: Desestruturação do Estado e Perda de Direitos. 2 ed. São Paulo: Editora Cortez, 2003.

BRASIL. Código de Ética do/a Assistente Social. Lei 8.662/93 de regulamentação da profissão. - 10. ed. rev. e atual. - [Brasília]: Conselho Federal de Serviço Social, 2012.

BRAZ, M; TEIXEIRA, J. O projeto ético-político do Serviço Social. In: Serviço Social: direitos sociais e competências profissionais. Brasília: CFESS/ABPESS, 2009.

CAVALCANTE, E. B.; OLIVEIRA, J. S.; MARQUES, M. D. R. O Serviço Social previdenciário, a transformação digital no INSS pré-pandemia e os agravos diante do Coronavírus: um relato de experiência. In: PEREIRA, S. L. B; CRONEMBERGER, I. H. G. M. (org). Serviço Social em Tempos de Pandemia: provocações ao debate. Cap. 14. Teresina: EDUFPI, 2020. Disponível em: https://ufpi.br/arquivos_download/arquivos/Servi\%C3\%A7o_Social_em_tempos_de_pandemia_provoc a\%C3\%A7\%C3\%B5es_ao_debate_120200923104616.pdf. Acesso em: 10 dez. 2020.

CFESS MANIFESTA. Os impactos do Coronavírus no trabalho do/a assistente social. 2020. Disponível em:http://www.cfess.org.br/arquivos/2020CfessManifestaEdEspecialCoronavirus.pdf. Acesso em: 10 dez. 2020.

CFESS. ORIENTAÇÃO NORMATIVA Nº. 3/2020. Dispõe sobre ações de comunicação de boletins de saúde e óbitos por Assistentes Sociais. Disponível em:

http://www.cfess.org.br/visualizar/menu/local/normativas-do-cfess. Acesso em: 18 dez. 2020.

DELUCHEY, Jean Francois Y. Biopolítica e Morte no Brasil 0 Extermínio da juventude negra (ultra)periférica na Amazônia, 2019. (Relatório de pesquisa).

GEPSS. A realidade dos(das) assistentes sociais no estado do Pará: estudo sobre a formação e atuação profissional no contexto de avanço neoliberal e desmonte das políticas sociais pós-golpe institucional de 2016. Relatório de Pesquisa, Belém: UFPA, 2018.

GOMES, C. C. A; VERAS, M. M. Política de Assistência Social e População em Situação de Rua e as estratégias de acolhimento durante a Pandemia do Coronavírus em Teresina-PI. In: PEREIRA, S. L. B; CRONEMBERGER, I. H. G. M. (org). Serviço Social em Tempos de Pandemia: provocações ao debate. Cap. 11. Teresina: EDUFPI, 2020. Disponível em:

https://ufpi.br/arquivos_download/arquivos/Servi\%C3\%A7o_Social_em_tempos_de_pandemia_provoc a\%C3\%A7\%C3\%B5es_ao_debate_120200923104616.pdf. Acesso em: 10 dez. 2020.

HARVEY, David. O Neoliberalismo: História e Implicações. São Paulo, Edições Loyola, 2008.

IAMAMOTO, M. V. As Dimensões Ético-políticas e Teórico-metodológicas no Serviço Social Contemporâneo. In: Mota AE, (org.). Serviço Social e Saúde: Formação e Trabalho Profissional. São Paulo: OPAS, OMS, MS; 2006. p. 1-37. 
Os espaços sócio-ocupacionais do assistente social. In: Serviço Social: direitos sociais e competências profissionais. Brasília: CFESS/ABPESS, 2009.

IPEA, Instituto de Pesquisa Aplicada. Atlas da Violência 2020. Disponível em: https://www.ipea.gov.br/atlasviolencia/download/24/atlas-da-violencia-2020. Acesso em: 28 ago. 2020.

LEAL, C. M.; OLIVEIRA, L. B.; BATISTA, M. G. Gênero e Políticas Públicas para Mulheres em Tempos de Pandemia: a experiência da secretaria municipal de políticas públicas para mulheres de Teresina. In: PEREIRA, S. L. B; CRONEMBERGER, I. H. G. M. (org). Serviço Social em Tempos de Pandemia: provocações ao debate. Cap. 12. Teresina: EDUFPI, 2020. Disponível em: https://ufpi.br/arquivos_download/arquivos/Servi\%C3\%A7o_Social_em_tempos_de_pandemia_provoc a\%C3\%A7\%C3\%B5es_ao_debate_120200923104616.pdf. Acesso em: 10 dez. 2020.

MARX. K. Miséria da filosofia. São Paulo: Expressão Popular, 2009.

Para a questão judaica. São Paulo: Expressão Popular, 2009.

; ENGELS, F. Obras escolhidas em três volumes. Rio de Janeiro: Vitória, 1963. v. 3.

MATOS, Maurílio Castro de. A Pandemia do Coronavírus (COVID-19) e o trabalho de Assistentes Sociais na Saúde. In: Pela Saúde, Rio de Janeiro: Blogspot, 2020. Disponível em:http://www.cresses.org.br/wp-content/uploads/2020/04/Artigo-A-pandemia-do-coronav\%C3\%ADrus-COVID-19-e-otrabalho-de-assistentes-sociais-na-sa\%C3\%BAde-2.pdf. Acesso em: 28 nov. 2020.

MENDES, Gardene Leão. O mito da periculosidade do jovem na mídia imprensa Goiana. In: XV Congresso de Ciências da Comunicação na RegiãoCentro-Oeste, Rio Verde (GO), 2013.

MENEGAT, Marildo. 0 olho da barbárie. São Paulo: Expressão Popular, 2006

MÉSZÁROS, Istvan. 0 século XXI: socialismo ou barbárie? Boitempo: São Paulo, 2013.

MINISTÉRIO DA SAÚDE. Disponível em: https://covid.saude.gov.br/. Acesso em: 8 dez. 2020.

NETTO, J. P. Palestra de abertura. XIX Conferência Mundial da Federação Internacional dos Trabalhadores Sociais. Salvador/Bahia, agosto de 2008.

NAVARRO, Vicenç. As consequências do neoliberalismo na pandemia atual. Disponível em: https://www.cartamaior.com.br/?/Editoria/Politica/As-consequencias-do-neoliberalismo-na-pandemiaatual/4/46945. Acesso em: 3 jun. 2020.

OLIVEIRA, J. F. M. O Serviço Social no Atendimento às Situações de Violação de Direitos Durante a Pandemia COVID-19: relato de experiência em um Centro de Referência Especializada da Assistência Social (CREAS) de Teresina. In: PEREIRA, S. L. B; CRONEMBERGER, I. H. G. M. (org). Serviço Social em Tempos de Pandemia: provocações ao debate. Cap. 10. Teresina: EDUFPI, 2020. Disponível em: https://ufpi.br/arquivos_download/arquivos/Servi\%C3\%A7o_Social_em_tempos_de_pandemia_provoc a\%C3\%A7\%C3\%B5es_ao_debate_120200923104616.pdf. Acesso em: 10 dez. 2020. 
RESOLUÇÃO CFESS n 493/2006. Dispõe sobre as condições éticas e técnicas do exercício profissional do assistente social.Disponivel em: http://www.cfess.org.br/arquivos/Resolucao_49306.pdf. Acesso em: 3 jun. 2020.

SAMPAIO, J.R.C.; SCHÜZ, G.E. A epidemia de doença pelo vírus Ebola de 2014: o Regulamento Sanitário Internacional na perspectiva da Declaração Universal dos Direitos Humanos. Cad. Saúde Colet. v. 24, jun. 2016, Rio de Janeiro,

SANTOS, M. T; MANFROI, V. M. Condições de trabalho das/os assistentes sociais: precarização ética e técnica do exercício profissional. Em pauta, n. 36, p. 178-196, Rio de Janeiro, 2015. Disponível em: https://www.e-publicacoes.uerj.br/index.php/revistaempauta/article/view/21057. Acesso em: 10 dez. 2020.

SILVA, A. G. R.; SILVA, A. K. P. Panorama do Processo de Trabalho do Serviço Social na Unidade Integrada de Saúde do Mocambinho: relato de experiência no contexto da pandemia do novo coronavírus - COVID-19. In: PEREIRA, S. L. B; CRONEMBERGER, I. H. G. M. (org). Serviço Social em Tempos de Pandemia: provocações ao debate. Cap. 1. Teresina: EDUFPI, 2020.

SILVA, Gabriela do Nascimento Carvalho et al. A PANDEMIA DO NOVO CORONAVÍRUS E A RESSIGNIFICAÇÃO DO FAZER PROFISSIONAL DO ASSISTENTE SOCIAL NA SAÚDE. Revista Interfaces: Saúde, Humanas e Tecnologia, v. 8, n. 3, p. 724-732, 2020.

SILVA, Mossicleia Mendes. Sistema Único de Assistência Social: Entre o desmonte e a condição de serviço essencial no contexto da pandemia. In: MOREIRA, Elaine. GOUVEIA, Rachel. et al. (org.) Em tempos de Pandemia Propostas para a defesa da vida e de direitos sociais. Rio de Janeiro, UFRJ, Centro de Filosofia e Ciências Humanas. Escola de Serviço Social, 2020.

SOARES, Raí Vieira; NOBRE, Maria Cristina de Queiroz. O Golpe de Estado no Brasil em 2016 e Inflexões na Política de Educação Superior. Revista de Políticas Públicas, [S.I.], v. 22, n. 2, p. 799822, 7 jan. 2019. Universidade Federal do Maranhão. Disponível em: https://www.redalyc.org/jatsRepo/3211/321158845010/321158845010.pdf . Acesso em: 7 dez. 2020.

VALE, M. E. G.; NASCIMENTO, Y. B. Serviço Social e a COVID-19 no Hospital Universitário do Piauí (HU-UFPI): em cena os setores da oncologia e UTI. In: PEREIRA, S. L. B; CRONEMBERGER, I. H. G. M. (Org). Serviço Social em Tempos de Pandemia: provocações ao debate. Cap. 4. Teresina: EDUFPI, 2020. Disponível em: https://ufpi.br/arquivos_download/arquivos/Servi\%C3\%A7o_Social_em_tempos_de_pandemia_provoc a\%C3\%A7\%C3\%B5es_ao_debate_120200923104616.pdf. Acesso em: 10 dez. 2020.

VARELLA, Drauzio. Síndrome respiratória do Oriente Médio (MERS). Disponível em: https://drauziovarella.uol.com.br/doencas-e-sintomas/sindrome-respiratoria-do-oriente-medio-mers/. Acesso em: 15 dez. 2020.

\section{Notas}

1 Em 2016 no Brasil se efetiva um processo de impeachment de Dilma Rousseff, que fica popularizado como um golpe de Estado (Oliveira, T. B. de. 2017). 
20 surto do vírus Ebola ocorreu na África Ocidental, principalmente nos países de Guiné, Serra Leoa e Libéria, foi declarado oficialmente uma epidemia em 2014 (SAMPAIO; SCHÜTZ, 2016). Já a SARS foi uma síndrome respiratória grave causada pelo SARS-COVID, em 2002 na China e que se espalhou pelos continentes nos anos de 2003 e 2004. A síndrome respiratória do Oriente Médio (MERS) é uma doença provocada por outra variante dos coronavírus, o MERS-COV, segundo Drauzio Varella (2015). 